\section{Commentary: Another way to skin a cat, hardly ever}

\author{
Bahaaldin Alsoufi, MD
}

In the current issue of the Journal, Salve and colleagues ${ }^{1}$ present a small case series of 13 patients who underwent a novel modified pulmonary artery band (PAB) technique as part of initial palliation of complex cardiac anomalies (years 2004-2020). In their modified PAB technique, a restrictive interposition graft was used to reconstruct the main pulmonary artery between the pulmonary root and the distal pulmonary confluence, functioning as a modified PAB. The weight and anatomy determined the diameter and length of the interposition graft. The vast majority of patients (12/13) underwent concomitant arterial switch operation. The intended final strategy was single ventricle $(n=6)$, one-and-half ventricle $(n=1)$, and biventricular repair $(n=6)$. All patients survived, and the authors didn't report any unplanned $\mathrm{PAB}$ reintervention. The authors present this modified PAB, along with concomitant arterial switch operation as an alternative strategy to PAB alone in patients with transposed great vessels, given the difficulty in banding these patients, mainly because of the streaming effect into the aorta with subsequent cyanosis that complicates adequate banding. The authors chose this modified technique of interposition graft as it is more likely to provide controlled and more predictable restriction of the pulmonary blood flow than traditional PAB, with lower risk of dislodgement and consequent distortion of the pulmonary valve or pulmonary artery branches.

What the authors from Australia are describing in this report is: (1) an alternative management strategy performing concomitant arterial switch operation and PAB, plus/

\footnotetext{
From the Department of Cardiovascular and Thoracic Surgery, University of Louisville School of Medicine, Norton Children's Hospital, Louisville, Ky. Disclosures: The author reported no conflicts of interest.

The Journal policy requires editors and reviewers to disclose conflicts of interest and to decline handling or reviewing manuscripts for which they may have a conflict of interest. The editors and reviewers of this article have no conflicts of interest.

Received for publication Aug 1, 2021; revisions received Aug 1, 2021; accepted for publication Aug 3, 2021; available ahead of print Aug 8, 2021.

Address for reprints: Bahaaldin Alsoufi, MD, Department of Cardiovascular and Thoracic Surgery, University of Louisville School of Medicine, Norton Children's Hospital, 201 Abraham Flexner Way, Suite 1200, Louisville, KY 40202 (E-mail: balsoufi@hotmail.com).

JTCVS Techniques 2021;9:121-3

2666-2507

Copyright (c) 2021 The Author(s). Published by Elsevier Inc. on behalf of The American Association for Thoracic Surgery. This is an open access article under the CC BY-NC-ND license (http://creativecommons.org/licenses/by-nc-nd/4.0/).

https://doi.org/10.1016/j.xjtc.2021.08.009
}

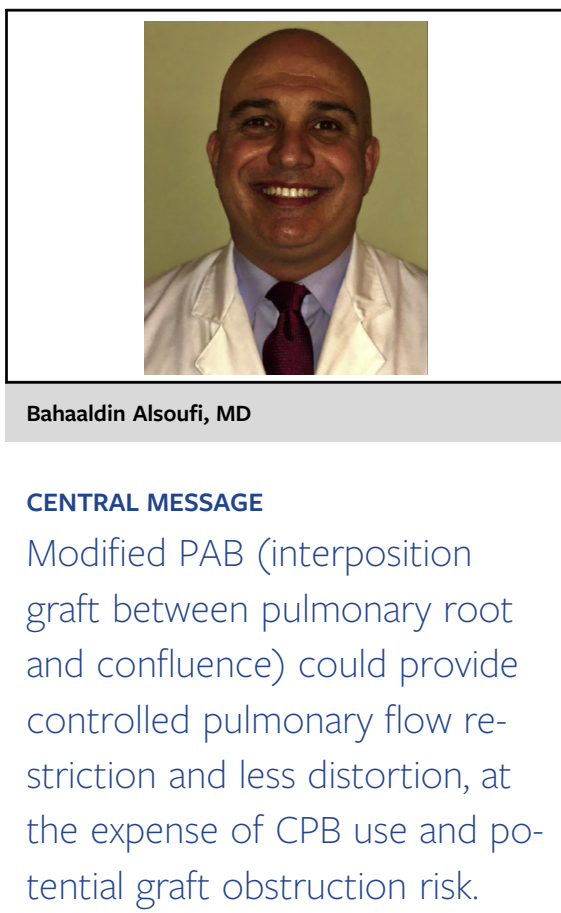

minus aortic arch repair as initial palliation and (2) an alternative technique of interposition graft rather than traditional PAB. For me, I feel that the modified PAB technique and the management strategy should be addressed separately.

First, the technique of interposition graft rather than traditional PAB. The authors are correct to point out the many potential disadvantages of traditional $\mathrm{PAB}$, such as dislodgement with subsequent distortion of the pulmonary artery branches or pulmonary valve, and that can be very important when the pulmonary valve is intended as the future systemic valve (eg, after later arterial switch operation or Damus-Kaye-Stansel connection). An additional disadvantage of the traditional PAB is the unpredictable restriction of pulmonary blood flow with the band too loose or too tight, complicating early and late management and potentially necessitating reintervention. ${ }^{2}$ The interposition graft is likely to produce a more controlled restriction of pulmonary blood flow, with less pulmonary valve or pulmonary artery distortion, and that is a clear advantage over traditional PAB. Nonetheless, this comes at the expense of the use of cardiopulmonary bypass that is not necessary when traditional $\mathrm{PAB}$ alone is used. Additionally, as in every shunt, there is a concern of graft stenosis or thrombosis that could be associated with serious consequences, although this was not reported in the authors' series. Therefore, it is unlikely that this report would entice surgeons to abandon 
traditional PAB technique except for cases in which $\mathrm{PAB}$ is used concomitantly with additional surgery that requires the use of cardiopulmonary bypass (similar to the experience from the authors' own experience). The tradeoff between the risk of pulmonary valve and pulmonary artery branches distortion and the potential risk of graft obstruction should be weighed in based on anatomic and demographic factors (for example, in a singleventricle patient where the pulmonary valve is not needed in the future, the risk of graft obstruction could outweigh the risk of pulmonary valve distortion).

Second, the strategy of arterial switch operation and $\mathrm{PAB}$, plus/minus aortic arch reconstruction. For that, we need to distinguish between patients with single-ventricle anomalies and those with cardiac anomalies amenable to biventricular repair. In the latter group, the most common defect is Taussig-Bing or other complex transposition of the great arteries anomalies. For these defects, advances in surgical and perfusion techniques and perioperative care have allowed primary total repair in the majority of patients. ${ }^{3}$ There are, however, a number of patients who might benefit from initial palliation, such as those with multiple ventricular septal defects or double-outlet right ventricle requiring complex intracardiac baffle in the setting of a very small-sized patient. In these cases, arterial switch operation, plus/minus aortic arch reconstruction as needed, in addition to PAB might be a reasonable strategy that allows surgeons to defer complex intracardiac repair to later stage. While traditional PAB of the reconstructed neopulmonary root has been habitually performed, I feel that the modification that the authors have described makes sense owing to the aforementioned advantages. In contrast, in patient with single-ventricle anomalies, I struggle to find a clear indication for this strategy. (1) In patients with no systemic or aortic arch obstruction and unrestricted pulmonary blood flow, traditional PAB without cardiopulmonary bypass is likely associated with less morbidity and is doable even in patients with transposed great arteries (understanding that one should exercise caution due to the higher risk of distortion of the pulmonary valve or the artery branches in a relatively shorter main pulmonary artery root). (2) In patients with no systemic obstruction but with arch obstruction that requires reconstruction on cardiopulmonary bypass and with unrestricted pulmonary blood flow, the modified PAB with interposition graft might make sense, given that the patients are exposed to cardiopulmonary bypass anyway. Nonetheless, these are very rare circumstances. ${ }^{4}$ (3) In patients with systemic outflow obstruction with or without arch obstruction and unrestricted pulmonary blood flow, the palliative switch operation has been proposed as an initial first stage palliation option. In these patients, the underlying single ventricle anomaly is commonly double inlet left ventricle or tricuspid atresia associated with transposed great arteries. The systemic obstruction is usually at the level of a restrictive bulboventricular foramen, and the association with aortic and arch hypoplasia is common. ${ }^{5}$ Proponents for the palliative switch operation suggest that this option could be associated with less neoaortic regurgitation, less entrapment of the left pulmonary artery, and more accessible pulmonary artery branches for future augmentation because of the Lecompte maneuver. Additionally, proponents of this approach believe that the restriction of pulmonary blood flow at the level of bulboventricular foramen following palliative switch could obviate the need for shunt or band. ${ }^{6}$ Nonetheless, while a handful of centers apply this strategy, the majority of surgeons continue to prefer modified Norwood-type palliation in these anomalies given the lack of evidence of superiority of palliative switch with regards to neo-aortic regurgitation and pulmonary artery growth, the fair need for PAB or shunt initially or as an interim operation prior to second stage, and the concern of late valvar and coronary complications following the arterial switch operation. ${ }^{6-8}$ My personal bias, similar to the majority of surgeons, is to perform a Norwood-type surgery in these patients. Nonetheless, if a surgeon choses to perform palliative switch in these patients, I believe that the modified $\mathrm{PAB}$ with interposition graft again makes sense.

In summary, the proposed modified PAB with interposition graft is valid technique that can be associated with more controlled pulmonary blood flow and less distortion of the pulmonary valve or pulmonary artery branches; albeit at the expense of cardiopulmonary bypass need and potential risk for graft obstruction. However, given the other available alternatives, the strategy of modified $\mathrm{PAB}$ and arterial switch is seldom needed and might be most applicable in the very rare patient with complex transposition anomalies when complicated intracardiac repair is better deferred to later stage.

\section{References}

1. Salve GG, Cole AD, Nicholson IA, Winlaw DS, Chard RB, Orr Y. Modified pulmonary artery banding: a novel strategy for balancing pulmonary blood flow with transposed great arteries. J Thorac Cardiovasc Surg Tech. 2021;9:111-20.

2. Alsoufi B, Manlhiot C, Ehrlich A, Oster M, Kogon B, Mahle WT, et al. Results of palliation with an initial pulmonary artery band in patients with single ventricle associated with unrestricted pulmonary blood flow. J Thorac Cardiovasc Surg. 2015;149:213-20.

3. Alsoufi B, Cai S, Williams WG, Coles JG, Caldarone CA, Redington AM, et al. Improved results with single-stage total correction of Taussig-Bing anomaly. Eur J Cardiothorac Surg. 2008;33:244-50.

4. Alsoufi B, McCracken C, Shashidharan S, Kogon B, Border W, Kanter K. Palliation outcomes of neonates born with single-ventricle anomalies associated with aortic arch obstruction. Ann Thorac Surg. 2017; 103:637-44.

5. Alsoufi B. Management of the single ventricle and potentially obstructive systemic ventricular outflow tract. J Saudi Heart Assoc. 2013;25:191-202.

6. Heinle JS, Carberry KE, McKenzie ED, Liou A, Katigbak PA, Fraser CD Jr. Outcomes after the palliative arterial switch operation in neonates with singleventricle anatomy. Ann Thorac Surg. 2013;95:212-8.

7. Alsoufi B, Slesnick T, McCracken C, Ehrlich A, Kanter K, Schlosser B, et al. Current outcomes of the Norwood operation in patients with single-ventricle malformations other than hypoplastic left heart syndrome. World J Pediatr Congenit Heart Surg. 2015;6:46-52. 
8. Alsoufi B, Al-Wadai A, Khan M, Al-Ahmadi M, Kalloghlian A, Bulbul Z, et al. Outcomes of Damus-Kaye-Stansel anastomosis at time of cavopulmonary connection in single ventricle patients at risk of developing systemic ventricular outflow tract obstruction. Eur J Cardiothorac Surg. 2014;45:77-82. 